\title{
Imaging of vascular remodeling after simulated thoracoabdominal aneurysm repair
}

\author{
Sarah Geisbüsch, MD, ${ }^{a}$ Deborah Schray, ${ }^{a}$ Moritz S. Bischoff, MD, ${ }^{a}$ Hung-Mo Lin, ScD, ${ }^{b}$ \\ Randall B. Griepp, MD, ${ }^{a}$ and Gabriele Di Luozzo, $\mathrm{MD}^{\mathrm{a}}$
}

Objective: A better understanding of the response of the spinal cord blood supply to segmental artery (SA) sacrifice should help minimize the risk of paraplegia after both open and endovascular repair of thoracoabdominal aortic (TAA) aneurysms.

\begin{abstract}
Methods: Twelve female juvenile Yorkshire pigs were randomized into 3 groups and perfused with a bariumlatex solution. Pigs in group 1 (control) had infusion without previous intervention. Pigs in group 2 were infused 48 hours after ligation of all SAs (T4-L5) and those in group 3 at 120 hours after ligation. Postmortem computed tomographic scanning of the entire pig enabled overall comparisons and measurement of vessel diameters in the spinal cord circulation.
\end{abstract}

Results: We ligated $14.5 \pm 0.8$ SAs: all filled retrograde to the ligature. Paraplegia occurred in $38 \%$ of operated pigs. A significant increase in the mean diameter of the anterior spinal artery (ASA) was evident after SA sacrifice $(P<.0001$ for 48 hours and 120 hours). The internal thoracic and intercostal arteries also increased in diameter. Quantitative assessment showed an increase in vessel density 48 hours after ligation of SAs, reflected by an obvious increase in small collateral vessels seen on 3-dimensional reconstructions of computed tomographic scans at 120 hours.

Conclusions: Remodeling of the spinal cord blood supply-including dilatation of the ASA and proliferation of small collateral vessels-is evident at 48 and 120 hours after extensive SA sacrifice. It is likely that exploitation of this process will prove valuable in the quest to eliminate paraplegia after TAA aneurysm repair. (J Thorac Cardiovasc Surg 2012;144:1471-8)

Although its incidence is gradually diminishing, paraplegia after surgery or endovascular treatment of thoracoabdominal aortic (TAA) aneurysms is still a devastating complication. The causes of spinal cord injury (SCI) are multifactorial, and different strategies for spinal cord protection have evolved over time. ${ }^{1}$ Despite this, when longer segments of the aorta are replaced-with more segmental arteries (SAs) sacrificed-the risk of SCI is still high. An understanding of the anatomic characteristics of the spinal cord vasculature is fundamental to knowing how to augment blood flow when surgery has compromised the usual sources of perfusion and thus to minimize the risk of paraplegia.

The initial detailed description of the spinal cord circulation was carried out by A. Adamkiewicz many years ago. ${ }^{2-5}$

\footnotetext{
From the Departments of Cardiothoracic Surgery ${ }^{\mathrm{a}}$ and Anaesthesiology, ${ }^{\mathrm{b}}$ Mount Sinai Medical Center, New York, NY.

This study was supported by grant R01 HL 045636 from the National Heart, Lung and Blood Institute.

Disclosures: Authors have nothing to disclose with regard to commercial support.

Read at the 38th Annual Meeting of The Western Thoracic Surgical Association,

Maui, Hawaii, June 27-30, 2012.

Received for publication June 11, 2012; revisions received July 30, 2012; accepted for publication Aug 23, 2012; available ahead of print Sept 24, 2012

Address for reprints: Sarah Geisbüsch, MD, Department of Cardiothoracic Surgery, Mount Sinai Medical Center, One Gustave L. Levy Pl, PO Box 1028, New York,

NY 10029 (E-mail: sarahgeisbuesch@hotmail.com).

$0022-5223 / \$ 36.00$

Copyright (c) 2012 by The American Association for Thoracic Surgery

http://dx.doi.org/10.1016/j.jtcvs.2012.08.062
}

His studies depict the presence of a distinctive SA in the lower thoracic/upper abdominal region, which he identified as being more important in supplying the anterior spinal artery (ASA) than other, smaller SAs. This artery has been referred to as the artery of Adamkiewcz ever since. Unfortunately, however, its identification is difficult and not always possible, and its reimplantation has been disappointing in its efficacy in reducing the incidence of SCI after aortic aneurysm repair. Likewise, a strategy involving reimplantation of multiple intercostal and lumbar arteries is not always successful in averting SCI; it entails risks such as subsequent patch aneurysms ${ }^{6}$ and is not feasible with an endovascular approach.

Lazorthes and associates ${ }^{2-4}$ were among the first to describe the important contribution of multiple other vessels to the spinal cord circulation and their anastomoses with one another. In addition to input from multiple intercostal and lumbar arteries, the vertebral arteries and branches of the subclavian and hypogastric arteries have now been recognized as part of the system nourishing the cord. ${ }^{5}$ Over time, experimental studies have enabled visualization in detail of the complex collateral network involved in spinal cord perfusion. ${ }^{7-9}$

$\mathrm{We}^{7}$ previously investigated the arterial network that supplies the spinal cord by infusing acrylic resin into the circulation: after tissue digestion, a cast of the collateral network was revealed, including a dense matrix of arteries in the 


\section{Abbreviations and Acronyms \\ ASA $=$ anterior spinal artery \\ $\mathrm{CT}=$ computed tomography \\ $\mathrm{SA}=$ segmental artery \\ SCI $=$ spinal cord injury \\ $\mathrm{TAA}=$ thoracoabdominal aorta (aortic)}

paraspinous musculature. This technique generated remarkably detailed images of vessel orientation, dimensions, and interconnections both in the native state and after sacrifice of segmental vessels. Our understanding of spinal cord protection has changed with the revelation of the extensive, dense collateral arterial system surrounding the cord; the major shortcoming of these studies involved the loss of casts of small vessels adjacent to ligatures, owing to lack of secondary support after tissue digestion, but they did allow visualization of a significant increase in the diameter of the ASA already 24 hours after sacrifice of SAs. On the basis of these findings, we hypothesize that the collateral network feeding the spinal cord quite rapidly increases its capacity in response to diminished input by means of both dilatation and development of new vessels.

We undertook the current study to further investigate the anatomic and physiologic response of the spinal cord vasculature to the sacrifice of all SAs. To study the vascular network more comprehensively and in greater detail and to avoid loss secondary to tissue digestion, we used a latexbarium mixture that can be visualized in situ with 3-dimensional computed tomographic (CT) scanning.

\section{METHODS}

Before the experiment, a pilot study was performed to determine the correct barium-latex mixture and optimal perfusion pressure to achieve filling of all vessels. All animals received humane care in compliance with the "Principles of Laboratory Animal Care" formulated by the National Society for Medical Research and the "Guide for the Care and Use of Laboratory Animals" published by the National Institutes of Health (NIH Publication No. 88-23, revised 1996). The study was approved by the Mount Sinai Institutional Research Committee.

Twelve female juvenile Yorkshire pigs (Animal Biotech Industries, Allentown, $\mathrm{NJ}$ ) weighing $25 \pm 2 \mathrm{~kg}$ (range, $23-28 \mathrm{~kg}$ ) were randomized into 3 groups before perfusion with a mixture of latex and barium. Two groups underwent sacrifice of all SAs T4-L5 before perfusion with the latex-barium mixture, and 1 group had no intervention before perfusion with the radiopaque mixture (control). The casting procedure was undertaken 48 hours after SA ligation in group 2 and was carried out 120 hours after SA ligation in group 3; group 1 was the control. Functional outcome was evaluated using the modified Tarlov score, as described in detail subsequently.

\section{SA Ligation}

After premedication with intramuscular ketamine $(15 \mathrm{mg} / \mathrm{kg})$ and atropine $(0.03 \mathrm{mg} / \mathrm{kg})$, an endotracheal tube is placed. The animals are then transferred to the operating room and are mechanically ventilated with an inspired oxygen fraction of 0.5 and a minute volume adequate for maintenance of a normal carbon dioxide tension $(35-40 \mathrm{~mm} \mathrm{Hg})$.
Anesthesia is induced via the bolus intravenous administration of propofol $(1 \mathrm{mg} / \mathrm{kg})$ and fentanyl $(50 \mu \mathrm{g} / \mathrm{kg})$. It is maintained with infusions of ketamine $\left(15 \mathrm{mg} \cdot \mathrm{kg}^{-1} \cdot \mathrm{h}^{-1}\right)$, propofol $\left(7 \mathrm{mg} \cdot \mathrm{kg}^{-1} \cdot \mathrm{h}^{-1}\right)$, and fentanyl $\left(5 \mu \mathrm{g} \cdot \mathrm{kg}^{-1} \cdot \mathrm{h}^{-1}\right)$. The pig is then cooled to $32^{\circ} \mathrm{C}$ using a cooling blanket. The chest is opened through a thoracotomy in the seventh intercostal space. The abdominal aorta is exposed through a left flank incision. The aorta is mobilized from the arch to the bifurcation with careful identification of the SAs as they arise from the aorta. The SAs are sacrificed serially in a cephalocaudal sequence. Once the procedure is completed, the incisions are closed and the animal is gradually rewarmed and weaned from anesthesia. After signs of awakening are evident, ventilatory support is gradually decreased until the animal is breathing spontaneously. Regular analgesic medication is administered: intramuscular buphrenorphine $(0.03 \mathrm{mg} / \mathrm{kg}$ bid) and a fentanyl patch (50 $\mu \mathrm{g} / \mathrm{h}$ for 72 hours).

During this procedure, a small arterial catheter is placed in the aorta and secured to the pig's back. This enables us to measure the blood pressure postoperatively and adjust intravenous fluids accordingly.

\section{Barium-Latex Infusion}

After heparinization (300 IU/kg), a 26F single-stage cannula is inserted into the right atrium and a $16 \mathrm{~F}$ arterial cannula into the aortic arch. Blood washout is accomplished with $4000 \mathrm{~mL}$ of $0.9 \%$ saline solution and 7500 IU of heparin. The reservoir of the pump is then loaded with $1 \mathrm{~L}$ of highviscosity latex (Blue Latex Solution; Ward's Natural Science, Rochester, NY) mixed with $360 \mathrm{~mL}$ of barium (Barium Sulfate Suspension; E-ZEM Canada Inc, Lake Success, NY). Whole-body perfusion is started at physiologic pressures while exsanguination is achieved through the venous cannula. The animal is anesthetized throughout the procedure and is humanely killed before being perfused with the carrier-barium sulfate mixture. Perfusion pressures are monitored through a right axillary and a femoral artery catheter. Peak pressure for saline perfusion is $100 \mathrm{~mm}$ $\mathrm{Hg}$ : it is $200 \mathrm{~mm} \mathrm{Hg}$ during latex perfusion to achieve complete filling of vascular structures. In 9 of 12 pigs, the latex was allowed to harden for 48 hours at $4^{\circ} \mathrm{C}$ before evisceration was carried out because it was found to be technically easier than carrying out evisceration after scanning. The pigs were then frozen at $-80^{\circ} \mathrm{C}$.

\section{CT Angiography}

CT scans of whole pigs were performed with a 256-slice multidetector CT scanner. The high-resolution scans were carried out at $140 \mathrm{kV}$ and $250 \mathrm{mAS}$. Slice thickness was $0.67 \mathrm{~mm}$, with an increment of $0.3 \mathrm{~mm}$. Three-dimensional reconstructions were undertaken to evaluate the data and measure vessel diameters.

\section{Measurements of Vessels and Calibration}

CT images were processed and analyzed using OsiriX version 3.9 software. In 3 pigs that were not eviscerated before they were frozen and scanned, the intestines were extracted from the images using the OsiriX software (Figures 1 and 2).

A frame of $568 \times 356$ pixels around the internal thoracic artery-with the beginning of the bifurcation acting as the midpoint of the left side of the rectangle-was excised. A $442 \times 227$ frame around the external iliac artery-beginning just above the external iliac artery, with the right corner meeting the right common iliac artery - was cropped to compare vessel density (see Figures 3 and 4). The GNU Image Manipulation Program histogram feature was used to analyze the regions of interest using gray values.

To achieve accuracy within our measurements, we performed a calibration and converted all measurements. Tubes of different known diameters were filled with the barium-latex mixture, inserted in the pig intraoperatively, and measured using the same filter we applied to measure vessels. Measured diameter was then multiplied by a factor that was calculated to achieve the actual diameter. A smooth curve was created to obtain appropriate multiplication factors for all vessel sizes. 


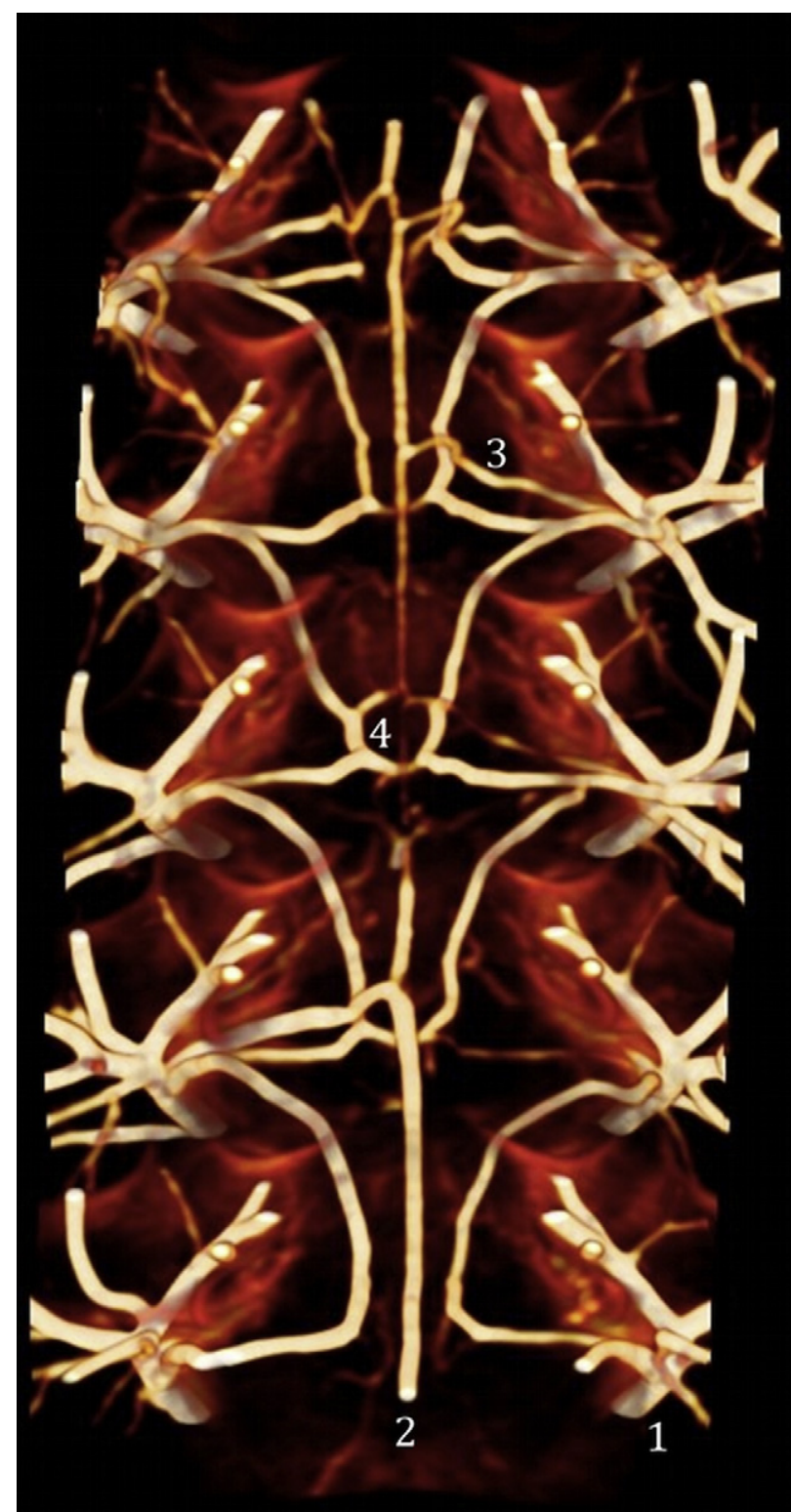

FIGURE 1. Computed tomographic image showing the anatomy of the anterior spinal artery and epidural arcades. The main trunks of the segmental arteries (1) feed the anterior spinal artery (2) through the anterior radicular-medullary artery (3), and give off branches to the epidural arcades (4).

\section{Behavioral Evaluation}

To evaluate functional outcome, we used a modified Tarlov scale, in which 0 indicates no voluntary movements; 1 , perceptible movements at joints; 2 , good movements at joints but inability to stand; 3 , ability to get up and stand with assistance for less than 1 minute; 4 , ability to get up with assistance and stand unassisted for less than 1 minute; 5 , ability to get up with assistance and stand unassisted for more than 1 minute; 6 , ability to get up and stand unassisted for more than 1 minute; 7 , ability to walk for less than 1 minute; 8 , ability to walk for more than 1 minute; and 9, full recovery.

\section{Statistical Analysis}

Data were entered in an Excel spreadsheet (Microsoft Corp, Redmond, Wash) and transferred to an SAS file (SAS Institute, Inc, Cary, NC) for data description and analysis. Descriptive data of the pigs are presented as percentages, medians with ranges, or means \pm standard deviations. A mixed model, with groups as the fixed effect and pigs within each group as the random effect, was used to compare the differences among the 3 groups. Least squares means (standard error) were reported.

\section{RESULTS}

The mean weight of the pigs was $25 \pm 2 \mathrm{~kg}$ (range, 23-28 $\mathrm{kg}$ ). The average number of SAs ligated was $14.5 \pm 0.8$ : all ligated SAs remained patent, filling retrograde to the ligatur site. Paraplegia occurred in $37.5 \%$ of operated pigs (3/8), as anticipated from previous studies in the same animal model. The latex-barium mixture was infused with a mean pressure of $177 \pm 20 \mathrm{~mm} \mathrm{Hg} ; 4242 \pm 448 \mathrm{~mL}$ of saline was used to wash the blood out, and $798 \pm 130 \mathrm{~mL}$ of the barium-latex mixture was infused.

\section{Group Comparisons}

Although comparisons were made between a control group of 4 pigs and 2 groups of 4 pigs each perfused at 48 and at 120 hours after SA sacrifice, the results and discussion are phrased in physiologic terms, as though measurements were occurring in the same animal over time: before intervention and then twice thereafter.

Vessel diameter. The mean diameter of the ASA in controls was $0.29 \pm 0.02 \mathrm{~mm}$ (Table 1). The ASA showed an increase of $59 \% \quad 48$ hours after SA sacrifice, to $0.46 \pm 0.02 \mathrm{~mm}(P<.0001)$, but no further increase at 120 hours $(0.43 \pm 0.02 ; P<.0001$ compared with controls). We also analyzed diameters of the ASA in the thorax (T4T13) and the lumbar area (L1-L5) separately. The diameter of the thoracic ASA increased $49 \%$ - from $0.33 \pm 0.05 \mathrm{~mm}$ in controls to $0.49 \pm 0.05 \mathrm{~mm}$ after 48 hours $(P=.02)$ - and by $36 \%$ - to $0.45 \pm 0.05 \mathrm{~mm}$-after 120 hours $(P=.07)$. In the lumbar ASA, we found an increased diameter of $0.43 \pm 0.03$ after 48 hours $(P=.0002)$ and $0.40 \pm 0.03$ after 120 hours $(P=.002)$ compared with $0.25 \pm 0.03 \mathrm{~mm}$ in controls. This represents an increase of $72 \%$ within 48 hours and $60 \%$ within 120 hours.

The diameter of the internal thoracic artery was $1.50 \pm 0.11 \mathrm{~mm}$ in controls, $1.53 \pm 0.11 \mathrm{~mm}$ after 48 hours and $1.81 \pm 0.11 \mathrm{~mm}$ after 120 hours $(P=.083)$. The intercostal arteries arising from ligated SAs measured $0.81 \pm 0.04$ in controls and increased with time, measuring $0.87 \pm 0.04 \mathrm{~mm}$ at 48 hours and $0.92 \pm 0.05 \mathrm{~mm}$ at 120 hours $(P=.27)$. The diameter of the iliolumbar arteries remained quite constant: $1.34 \pm 0.14 \mathrm{~mm}$ in controls, $1.35 \pm 0.14 \mathrm{~mm}$ in the 48-hour group, and $1.40 \pm 0.14$ $\mathrm{mm}$ at 120 hours $(P=.95)$.

Vessel density. A visually impressive increase in density of smaller collateral vessels was evident on CT scans by 48 and 120 hours postoperatively. When analyzing vessel density according to gray values on CT scans, we found that in the thoracic window (frame cropped around the internal 


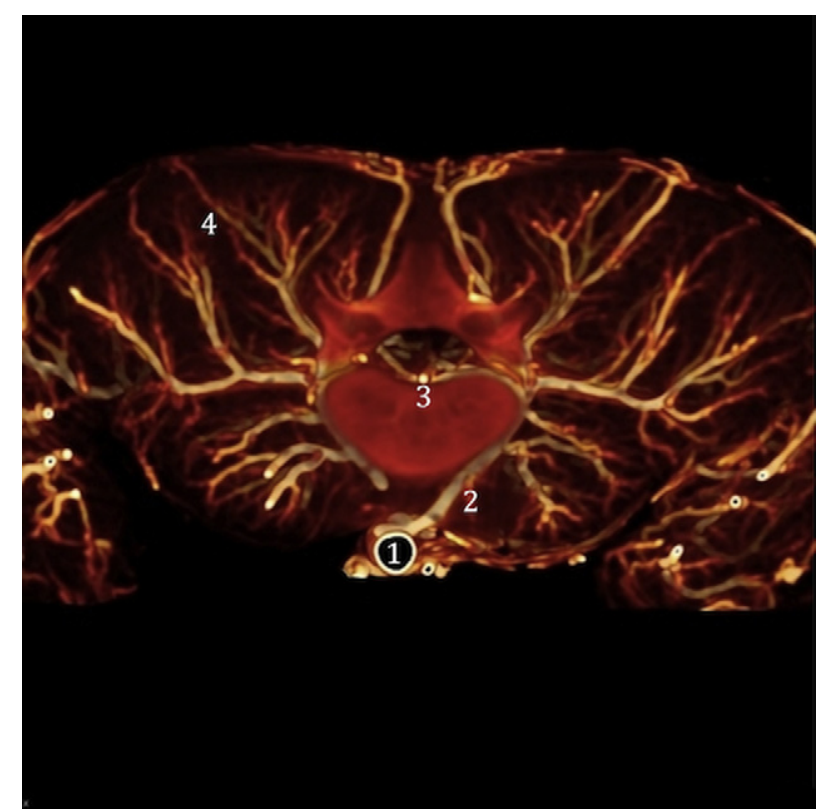

FIGURE 2. Vasculature of the spinal cord and the arterial network within the paraspinous muscles. The segmental artery (2) arises from the aorta (1) and runs around the vertebral body, connecting to the anterior spinal artery (3) through the anterior radicular-medullary arteries. Note the extensive network within the paraspinous muscle (4) and its interconnections with the segmental arteries.

thoracic artery) the percentage of gray value was higher at 48 hours than in the controls: $49 \% \pm 3 \%$ versus $37 \% \pm 4 \%$ (Figure $4, A)$. The percentage of gray value was $42 \% \pm 6 \%$ after 120 hours $(P=.09)$. In the lumbar window, there was also an increase in vessel density (Figure $4, B$ ), albeit not as significant: $48 \% \pm 4 \%$ of pixels in this window were counted as vessels in the unoperated group, with an increase to $56 \% \pm 2 \%$ after 48 hours and $58 \% \pm 7 \%$ after 120 hours $(P=.23)$.

\section{DISCUSSION}

Previous studies of vascular casts in our institution have already allowed a detailed description of the spinal cord and paraspinous muscle arterial network. Small arteries and arterioles were visualized with scanning electron microscopy. These studies provided insight into the mass of interconnected arteries, their orientation, and the importance of the SAs in providing nutrient blood not only to the spinal cord, but also, and predominantly, to paraspinous muscles. The current study of CT scanning of juvenile pigs infused with a latex-barium mixture has allowed further imaging of the collateral network and its response to sacrifice of SA input similar to what occurs with repair of descending aortic and thoracoabdominal aneurysms during either open surgery or endovascular repair. The high viscosity of the latex-barium mixture, which does not shrink after infusion, allows us to measure and calculate actual dimensions of the
ASA with greater accuracy. High-resolution multidetector CT scanning and 3-dimensional reconstruction of the entire pig enabled us to also include additional vessels-such as branches of the external iliac artery, the internal thoracic artery, and the intercostal arteries-in our analysis and discover significant changes in vessel diameter as well as vessel density triggered by SA sacrifice. Small interconnecting vessels up to a minimum diameter of $0.13 \mathrm{~mm}$ could be measured with accuracy, and computer-based definition of certain areas of interest with further analysis of pixel count enabled us to quantify vessel density.

The ASA is dilated 48 hours after sacrifice of all SAs, and the number of small interconnecting vessels-not only in the paraspinous region but also in areas around the internal thoracic artery and in the lumbar region-seems to increase over time. Overall vessel density increases impressively, likely in response to local ischemia. Evidence from this and earlier studies confirms that this process is already significant 48 hours after SA ligation and tends to become more robust by 5 days. This explains earlier physiologic observations, which showed that significantly lower values for spinal cord blood flow at 5 hours after SA sacrifice were seen in pigs with subsequent SCI than in those that recovered normal function. ${ }^{10}$ This suggests that critical spinal cord ischemia after complete sacrifice of all thoracoabdominal SAs does not occur immediately (intraoperatively) but is delayed 1 to 5 hours or longer after clamping and represents failure to mount a hyperemic response to rewarming and awakening. Immediate injury can be kept minimal or prevented with good intraoperative management such as hypothermia, spinal cord drainage, spinal cord monitoring, and distal perfusion. The reason for delayed paraplegia is usually an episode of hypotension that occurs before postoperative adaptation to a loss of input into the collateral network that supplies the spinal cord has had a chance to occur.

Taking together microsphere studies of blood flow, direct measurements of collateral network pressure, previous casting studies, and the observations from the current study, we can construct an approximate scenario of how the collateral network responds to extensive SA sacrifice. We know that blood flow takes 72 hours to recover reliably to preoperative levels and that the pressure in the collateral network takes up to 5 days to return to baseline values. In the previous casting studies, we saw an increase in the diameter of the ASA already at 24 hours and further enlargement at 5 days: in the current study, we see significant dilatation at 48 hours, with no significant further increase at 5 days. Thus it seems that the immediate response of the collateral network is to increase flow by means of dilatation of existing named vessels: the ASA, the epidural arcades, the internal thoracic artery, and the intercostal arteries.

Between 48 and 120 hours, the augmentation of blood flow seems to be a combination of generation of new small 

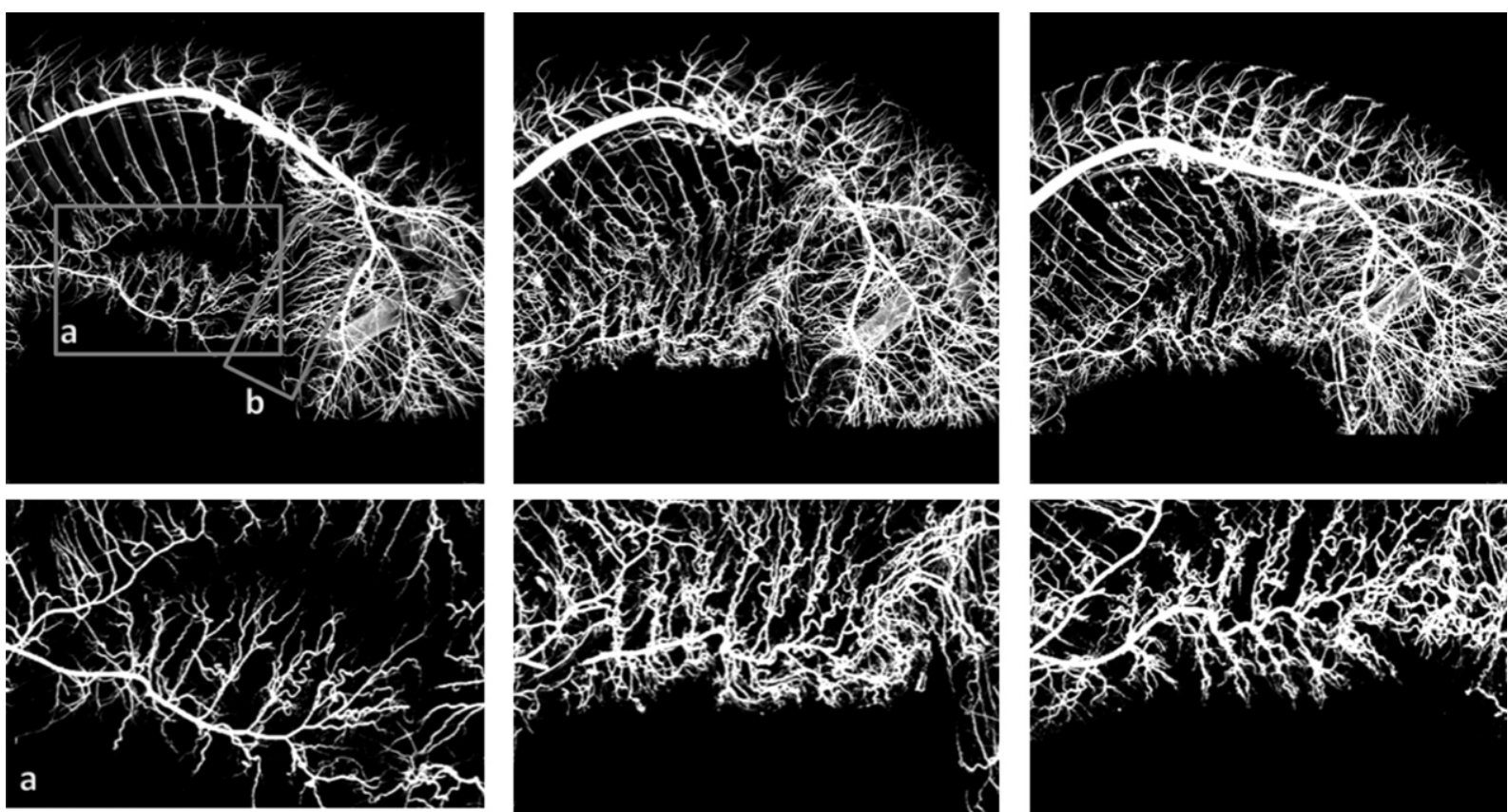

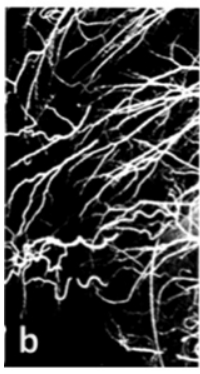

A

\section{native}

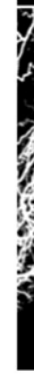 \\ 8}

B

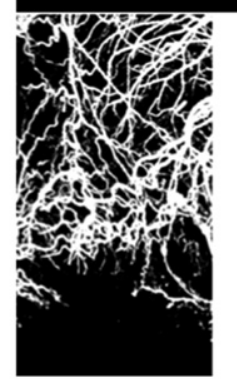

$120 \mathrm{~h}$

FIGURE 3. Computed tomographic image of the arterial vessel system of the entire pig. Bones, intestines, and other tissues were extracted from the image.

$\mathrm{A}, \mathrm{B}$, and $\mathrm{C}$ show examples of vessel casting for a native pig at 48 hours and at 120 hours after segmental artery ligation, respectively. A frame around the internal thoracic artery $(a)$ and around the iliolumbar vessel $(b)$ was cropped, and vessel density was compared between the groups. An impressive increase in density of small vessels could be seen, but no statistically significant differences could be demonstrated with the small number of pigs examined at each time point.

vessels—angiogenesis—and transformation of existing very small vessels into larger ones-arteriogenesis. Both of these mechanisms likely contribute to the increase in vascular density seen in the current study, which confirms the observation of increased vascular density made by morphometric analysis in the earlier study. The earlier study also showed a reorientation of these small vessels within the musculature to allow them to feed into the cranial and caudal collateral vessels providing flow to the lower thoracic ASA.

The increase of vessel density after SA sacrifice can clearly be appreciated in the CT images (see Figures 3 and 4). However, it is also apparent that there is some variability. The failure of 1 pig in the 120-hour group to show marked vascular changes likely influenced the outcome in this small study and did not allow us to demonstrate whether larger diameters and greater vessel densities are usually present at 120 hours as compared with 48 hours after SA sacrifice. The differences observed between individual pigs in this small study emphasize the likelihood that there is interindividual variability in the response of the collateral network to SA sacrifice.

However, all the studies combined leave no doubt that within 48 hours and certainly within 5 days, the collateral circulation has undergone profound changes to support spinal cord perfusion in the absence of antegrade flow through SAs to the ASA. Multiple vessels and their interconnections function to supply the spinal cord: not only does a dense network within the paraspinous muscles develop, but also other, larger vessels contribute to compensate for loss of direct inflow into the midthoracic region of the spinal cord. We were hoping to demonstrate significant increases in the diameters of several of these vessels, but interindividual variability made it difficult to demonstrate this conclusively, although a trend was apparent. 

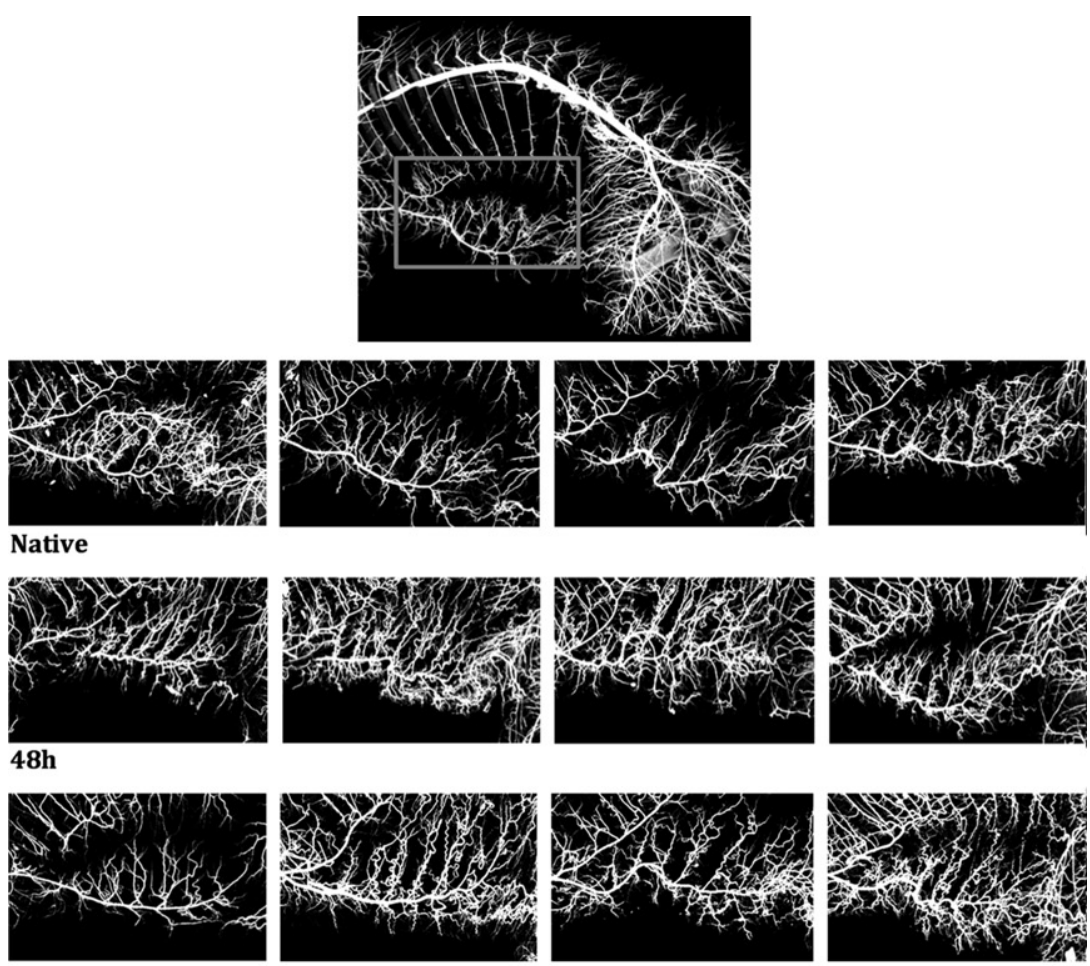

$$
120 \mathrm{~h}
$$

A
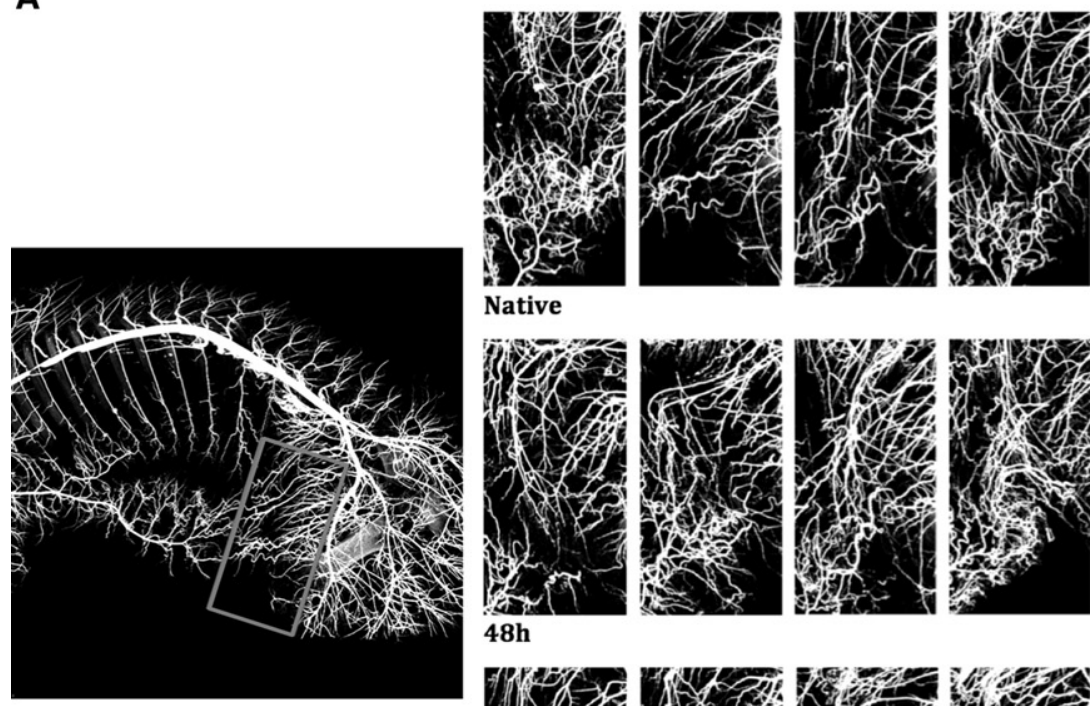

48h
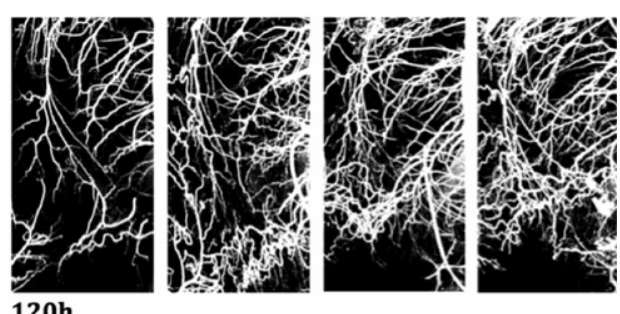

B

$120 \mathrm{~h}$

FIGURE 4. A, Analyzing the area around the right internal thoracic artery with the beginning of the bifurcation acting as the midpoint of the left side of the $568 \times 365$ rectangle. B, Analyzing the area around the right external iliac artery with the $442 \times 227$ rectangular frame being just above the external iliac artery and the right corner meeting the right common iliac artery. The images from all 4 pigs in each group are shown in 1 horizontal row. There is 1 pig in the group of native pigs and $1 \mathrm{pig}$ in the 120-hour pigs that did not show results consistent with the others, pointing to likely interindividual variability in the response of the collateral network to segmental artery sacrifice. 
TABLE 1. Least squares means (standard error) of vessel diameters (mm)

\begin{tabular}{|c|c|c|c|c|}
\hline & $\begin{array}{l}\text { Group 1 } \\
\text { (control) }\end{array}$ & Group 2 & Group 3 & $\begin{array}{c}P \\
\text { value }\end{array}$ \\
\hline ASA & $0.29 \pm 0.02$ & $0.46 \pm 0.02$ & $0.43 \pm 0.02$ & $\begin{array}{l}<.0001(1 \text { vs } 2) \\
<.0001(1 \text { vs } 3)\end{array}$ \\
\hline ASA thoracic & $0.33 \pm 0.05$ & $0.49 \pm 0.05$ & $0.45 \pm 0.05$ & $\begin{array}{l}.02(1 \text { vs } 2) \\
.07(1 \text { vs } 3)\end{array}$ \\
\hline ASA lumbar & $0.25 \pm 0.03$ & $0.43 \pm 0.03$ & $0.40 \pm 0.03$ & $\begin{array}{l}.0002 \text { (1 vs } 2) \\
.0020 \text { (1 vs } 3)\end{array}$ \\
\hline $\begin{array}{l}\text { Internal thoracic } \\
\text { artery }\end{array}$ & $1.50 \pm 0.11$ & $1.53 \pm 0.11$ & $1.81 \pm 0.11$ & .083 \\
\hline $\begin{array}{c}\text { Intercostal } \\
\text { arteries } \\
(\mathrm{T} 4-\mathrm{T} 13)\end{array}$ & $0.81 \pm 0.04$ & $0.87 \pm 0.04$ & $0.92 \pm 0.05$ & .273 \\
\hline $\begin{array}{l}\text { Iliolumbar } \\
\text { artery }\end{array}$ & $1.34 \pm 0.14$ & $1.35 \pm 0.14$ & $1.40 \pm 0.14$ & .951 \\
\hline
\end{tabular}

We confirmed the observation made in the previous casting study that the diameter of the ASA increases more significantly in the lumbar than in the thoracic region. This may be due to anatomic circumstances: the lumbar region of the spinal cord has a small peripheral and a large central supply, ${ }^{11}$ the latter arising from the ASA and perfusing two thirds of the spinal cord. In the thoracic region, central supply is less critical and the peripheral arterial supply is more significant. Mechanisms to increase peripheral blood flow-possibly an increase in size of the posterior spinal arteries in the thoracic area-may be activated by SA ligation. The fact that the ASA contributes less to spinal cord perfusion in the thoracic part of the cord may be one of the reasons the increase in size of the ASA is more prominent in the lumbar region, where central supply is dominant.

Previous studies have shown a significant increase in all regions of the ASA, although the increase in the caudal and cranial ends was more pronounced. ${ }^{7,8}$ The intercostal arteries that were ligated (Th4-Th13/L1; ribs 6-15/16) during operation also showed an increase in size. This increase was most impressive in vessels along the mid-tolower thoracic ribs. Given the observations of our studies and evidence from multiple previous studies ${ }^{2-5}$ that the most cervical and caudal parts of the cord are connected to the subclavian and internal iliac arteries, the changes in the collateral network that we observed in response to SA sacrifice are likely due to a sequence beginning with dilatation and then involving arteriogenesis and angiogenesis as well as vessel reorientation. In areas far from major collaterals, adaptation to relative ischemia may involve development of new vessels rather than an increase in the size of existing ones.

No single adjustment in operative technique can as yet prevent paraplegia after extensive thoracoabdominal aneurysm repair. Knowing that an impressive network of collaterals builds up within 5 days after ligating SAs-by means of dilatation, angiogenesis, and arteriogenesis-is essential to exploring the efficacy of various strategies for improving postoperative spinal cord perfusion. Stimulating vascular remodeling as well as augmenting cardiac output to increase flow through the collateral network are possible strategies. A multifaceted approach may be more effective than the current strategy, which is largely limited to shortterm efforts to increase mean arterial pressure postoperatively. An adequate pressure is of unquestioned importance in increasing perfusion within the collateral network, especially in conjunction with spinal cord drainage, but may not be sufficient or sustained enough to prevent delayed paraplegia. In addition, precise control and maintenance of sufficiently high blood pressure is sometimes impractical in patients who are chronically hypertensive, bleeding, or hemodynamically unstable.

Although replacement of the entire TAA during a single procedure still carries a significant risk of SCI, results from experimental studies as well as clinical experience at our institution suggest that paraplegia and paraparesis are almost never seen-even with an equivalently extensive total resection-if aneurysm repair is carried out in stages, with abdominal replacement after thoracic replacement (or vice versa) after an interval of weeks, months, or years. ${ }^{12-14}$ Various existing reports identify patients undergoing endovascular thoracic aortic aneurysm repair after previous or concomitant abdominal aortic repair to be at higher risk for SCI. ${ }^{15-19}$ However, the largest and most recent single-center study in which a hybrid procedure was performed in 47 patients-33 simultaneous abdominal and thoracic aortic repairs and 14 staged proceduresfound the staged approach to be superior. Their overall paraplegia rate was $4.3 \%$, comparable with results after open TAA repair. Both of the subsequently paraplegic patients had undergone simultaneous repair. ${ }^{20}$

Causes for paraplegia are multifactorial; optimal intraoperative as well as postoperative care is needed to prevent this devastating complication. The extent of aneurysm repair is nevertheless the most important factor: not only does the number of SAs sacrificed matter, but also the additional occlusion or compromise of vessels feeding into the collateral network, such as the subclavian and hypogastric arteries influences recovery after SA sacrifice. Patients undergoing combined open and endovascular procedures may have had these major sources of collateral flow impinged on during earlier operations. At present, patients undergoing hybrid repairs tend also to have more comorbidities than patients having open surgical repair, and therefore perioperative management may be more difficult, leading to complications including paraplegia. We speculate that reduced paraplegia rate clearly seen after staged procedures separated by several days to weeks or months is due to 
development of additional collateral vessels in the time between the 2 operations, which compensates for the loss of the SAs. The questions now being explored include the minimum interval required for adequate stable enhancement of the collateral network after the first stage of a 2-stage procedure, the minimum stimulus required for such enhancement to be initiated, and how one can ascertain that the necessary augmentation of the collateral system has been induced and/ or achieved in any individual instance.

At present, an effective strategy for minimizing the occurrence of postoperative paraplegia is the deliberate staging of extensive thoracoabdominal resections where clinically feasible. Possible future approaches include induction of a collateral network response before the definitive operation using pharmacologic, minimally invasive, or endovascular strategies. An understanding of the anatomy and pathophysiology of the collateral network response to SA sacrifice will help in the development of such strategies, which we expect will ultimately eliminate the problem of postoperative paraplegia after extensive TAA resection.

\section{CONCLUSIONS}

In this experimental simulation of TAA aneurysm repair, remodeling of the blood supply to the spinal cord is evident at 48 to 120 hours and is characterized by recruitment and dilatation of small unnamed vessels and by dilatation of some major axial vessels. Exploitation of our understanding of the collateral network response to loss of SA input is likely to prove invaluable in the quest to eliminate postoperative paraplegia after treatment of extensive thoracoabdominal aneurysms.

\section{References}

1. Shimizu H, Yozu R. Current strategies for spinal cord protection during thoracic and thoracoabdominal aortic aneurysm repair. Gen Thorac Cardiovasc Surg. 2011;59:155-63.

2. Lazorthes G, Gouaze A, Zadeh JO, Santini JJ, Lazorthes Y, Burdin P. Arterial vascularization of the spinal cord. Recent studies of the anastomotic substitution pathways. J Neurosurg. 1971;35:253-62.

3. Lazorthes G, Poulhes J, Bastide G, Roulleau J, Chancholle AR. [Research on the arterial vascularization of the medulla; applications to medullary pathology]. Bull Acad Natl Med. 1957;141:464-77.
4. Lazorthes G, Poulhes J, Bastide G, Roulleau J, Chancholle AR. [Arterial vascularization of the spine; anatomic research and applications in pathology of the spinal cord and aorta]. Neurochirurgie. 1958;4:3-19.

5. Adamkiewicz A. Die Blutgefaesse des menschlichen Rueckenmarks. S B Heidelberg Akad Wiss. 1882;101-30.

6. Kulik A, Castner CF, Kouchoukos NT. Outcomes after thoracoabdominal aortic aneurysm repair with hypothermic circulatory arrest. J Thorac Cardiovasc Surg. 2011;141:953-60.

7. Etz CD, Kari FA, Mueller CS, Silovitz D, Brenner RM, Lin HM, et al. The collateral network concept: a reassessment of the anatomy of spinal cord perfusion. J Thorac Cardiovasc Surg. 2011;141:1020-8.

8. Etz CD, Kari FA, Mueller CS, Brenner RM, Lin HM, Griepp RB. The collateral network concept: remodeling of the arterial collateral network after experimental segmental artery sacrifice. J Thorac Cardiovasc Surg. 2011;141:1029-36.

9. Strauch JT, Lauten A, Zhang N, Wahlers T, Griepp RB. Anatomy of spinal cord blood supply in the pig. Ann Thorac Surg. 2007;83:2130-4.

10. Etz CD, Homann TM, Luehr M, Kari FA, Weisz DJ, Kleinman G, et al. Spinal cord blood flow and ischemic injury after experimental sacrifice of thoracic and abdominal segmental arteries. Eur J Cardiothorac Surg. 2008; 33:1030-8.

11. Martirosyan NL, Feuerstein JS, Theodore N, Cavalcanti DD, Spetzler RF, Preul MC. Blood supply and vascular reactivity of the spinal cord under normal and pathological conditions. J Neurosurg Spine. 2011;15:238-51.

12. Bischoff MS, Scheumann J, Brenner RM, Ladage D, Bodian CA, Kleinman G, et al. Staged approach prevents spinal cord injury in hybrid surgicalendovascular thoracoabdominal aortic aneurysm repair: an experimental model. Ann Thorac Surg. 2011;92:138-46.

13. Zoli S, Etz CD, Roder F, Brenner RM, Bodian CA, Kleinman G, et al. Experimental two-stage simulated repair of extensive thoracoabdominal aneurysms reduces paraplegia risk. Ann Thorac Surg. 2010;90:722-9.

14. Etz CD, Zoli S, Mueller CS, Bodian CA, Di Luozzo G, Lazala R, et al. Staged repair significantly reduces paraplegia rate after extensive thoracoabdominal aortic aneurysm repair. J Thorac Cardiovasc Surg. 2010;139:1464-72.

15. Dake MD, Miller DC, Mitchell RS, Semba CP, Moore KA, Sakai T. The "first generation" of endovascular stent-grafts for patients with aneurysms of the descending thoracic aorta. J Thorac Cardiovasc Surg. 1998;116:689-703; discussion 704-4.

16. Gravereaux EC, Faries PL, Burks JA, Latessa V, Spielvogel D, Hollier LH, et al. Risk of spinal cord ischemia after endograft repair of thoracic aortic aneurysms. J Vasc Surg. 2001;34:997-1003.

17. Makaroun MS, Dillavou ED, Kee ST, Sicard G, Chaikof E, Bavaria J, et al. Endovascular treatment of thoracic aortic aneurysms: results of the phase II multicenter trial of the GORE TAG thoracic endoprosthesis. J Vasc Surg. 2005;41:1-9.

18. Schlosser FJ, Verhagen HJ, Lin PH, Verhoeven EL, van Herwaarden JA, Moll FL, et al. TEVAR following prior abdominal aortic aneurysm surgery: increased risk of neurological deficit. J Vasc Surg. 2009;49:308-14; discussion 314.

19. Martin DJ, Martin TD, Hess PJ, Daniels MJ, Feezor RJ, Lee WA. Spinal cord ischemia after TEVAR in patients with abdominal aortic aneurysms. J Vasc Surg. 2009;49:302-6; discussion 306-7.

20. Hughes GC, Barfield ME, Shah AA, Williams JB, Kuchibhatla M, Hanna JM, et al. Staged total abdominal debranching and thoracic endovascular aortic repair for thoracoabdominal aneurysm. J Vasc Surg. 2012;56:621-9. 